\title{
Personalism and cognitive labels as determinants of attitude attribution
}

\author{
STEPHEN G. WEST \\ Florida State University, Tallahassee, Florida 32306
}

\begin{abstract}
An experiment was conducted to test hypotheses derived from Jones and Davis' (1965) theory of correspondent inferences in conjunction with research on emotional misattribution effects. Subjects were informed that they had ingested either a stimulant or a tranquilizer (label). They then read an emotional, counterattitudinal essay which was written either personally for them or for another subject (personalism). The primary dependent variable was the attitude on the issue in question attributed to the author of the communication. The results showed that the subjects who read the more personal communication made more extreme attributions concerning the attitude of the author of the essay than did the subjects who read the less personal communication. In addition, subjects who were informed that they had received a tranquilizer made more extreme attitude attributions than subjects who were informed that they had received a stimulant. The implications of the results of the experiment for Jones and Davis' principles of personalism and hedonic relevance are discussed.
\end{abstract}

Jones and Davis (1965), in an extension of Heider's $(1944,1958)$ earlier work, have proposed a theory of correspondent inferences which describes the process through which an observer makes inferences about the causes of an actor's behavior. Those factors related to the characteristics of the behavior and the conditions under which it occurred have subsequently been demonstrated in empirical research (Jones, Davis, \& Gergen, 1961; Jones \& Harris, 1967; Jones, Worchel, Goethals, \& Grumet, 1971; Messick \& Reeder, 1972). However, two factors related to the observer's personal involvement in the action, hedonic relevance and personalism, have not been extensively investigated.

According to Jones and Davis, hedonic relevance is the net result of the positive and negative outcomes of an action for the observer. That is, hedonic relevance occurs whenever the action is gratifying or disappointing to the observer. Thus, hedonic relevance seems to consist of two components: (a) the degree to which the observer's goal attainment is facilitated or interfered with as a result of the action, and (b) the observer's positive or negative emotional response as a result of (a). When hedonic relevance is high, the observer should make more extreme dispositional attributions as to the cause of an action than when hedonic relevance is low. Support for this proposition is provided by an experiment by Jones and deCharms (1957) in which both of the components of hedonic rlevance were presumably manipulated. In this experiment, a confederate failed a task and this failure either prevented the subject from receiving a monetary reward (high hedonic relevance) or had no effect on the subject's receipt of the reward (low hedonic relevance). Jones and deCharms found that, in the high hedonic relevance condition, the confederate was rated as being less competent and less dependable than in the low hedonic relevance condition. While other experiments provide tangential support for this proposition (Deutsch, 1949; Kleiner, 1960; Steiner \& Field, 1960), the personality impression or attitude ratings necessary to adequately test the effects of hedonic relevance on the attribution process were not collected. No previous experiment has attempted to determine whether the two components which apparently comprise hedonic relevance are both necessary to influence the attribution process.

For an action to be high in the second factor related to the observer's personal involvement, personalism, it must meet two prerequisites (Jones, personal communication, 1970). (a) The observer must believe that the actor had some personal knowledge of him prior to the performance of the actions. (b) The observer must perceive the action as being specifically directed toward him and not toward people in general or a subclass of people in general (e.g., Blacks, agriculture students). If the two requirements are met and the act is therefore high in personalism, the action should be highly correspondent and thus the observer should make an extreme dispositional attribution as to the cause of the behavior. ${ }^{1}$ Jones and Davis (1965) do not elaborate the mechanism through which personalism influences the attribution process, except to suggest that high personalism may imply that the actor had a high degree of choice in performing the action.

Two experiments have been conducted relating to the proposition that high personalism leads to extreme attributions. Gergen (1962, cited in Jones, 1964) conducted an experiment in which subjects were interviewed by an actor under face-to-face (personal) 
conditions or over an intercom (impersonal). No difference was found in the personality impression ratings of the interviewer under the personal and impersonal conditions. In an experiment by Lowe and Goldstein (1970), subjects either received an evaluation from a confederate (involved condition) or witnessed another subject being evaluated (roleplaying condition). While subjects in the involved condition did make more extreme judgments of the evaluator's social perceptiveness than the role-playing subjects, they had also received an extreme positive or negative evaluation from this person. This suggests that differences in hedonic relevance as well as personalism may be responsible for the difference between the two conditions. Thus, Jones and Davis' proposition that high personalism leads to more extreme attributions has not been demonstrated empirically.

The present experiment was conducted to further investigate the effects of hedonic relevance and personalism on the attribution process. Since previous research (Jones \& deCharms, 1957) has demonstrated that when both conıponents of hedonic relevance (interference with goal attainment, emotional response) are apparently manipulated, subjects make more extreme attributions, the present experiment sought to determine whether the emotional response component is necessary to produce more extreme attributions. Research has demonstrated that the subject's emotional response to an arousing situation may be modified by leading the subject to misattribute his arousal to a placebo (Nisbett \& Schachter, 1966; Ross, Rodin, \& Zimbardo, 1969; Storms \& Nisbett, 1970), so that it should be possible to manipulate the subject's emotional response using this method while keeping his goal attainment constant.

To test this reasoning, a 2 by 2 design was employed, with the factors being the description of the effects of the drug given to the subject (label) and the personalism of an emotional counterattitudinal communication read by the subjects. First, it was predicted that subjects in the high-personalism condition would attribute a more extreme attitude (disposition) on the topic of the communication to the author of the essay than subjects in the low-personalism condition. Second, it was predicted that subjects who were led to believe they had received a stimulant should attribute a portion of their arousal to the pill, be less emotional, and therefore make a less extreme dispositional attribution than subjects who were led to believe that they had received a tranquilizer. The latter subjects should experience physiological arousal as a result of reading the emotional essay, while expecting this level to be reduced by the drug. Consequently, they should perceive the emotional communication as the source of their larger-than-expected arousal and become more emotional (cf. Storms \& Nisbett, 1970).

\section{METHOD}

\section{Subjects}

The subjects were 156 male introductory psychology students who had taken a battery of attitude and personality tests administered during the first week of classes. One to four subjects were run per experimental session, separated by partitions. In those sessions with more than one subject, the subjects were assigned to different experimental conditions.

\section{Procedure}

The subjects were given the cover story that the experiment was part of a research project which was investigating the interactive effects of two drugs and certain personality factors on verbal learning and memory. The experimenter then briefly outlined the tasks which the subjects would complete later in the experiment.

Following this introduction, all subjects were given a medical history questionnaire and consent form to fill out. The questionnaire listed a series of medical histories for which the use of a stimulant or tranquilizer might be contraindicated (e.g., epilepsy, kidney disorders). If the subject checked any of these questionable medical histories, he was eliminated from the experiment at this point. ${ }^{2}$

The subjects were then given a $\$ 00$ capsule, water, and a folded typewritten slip of paper. ${ }^{3}$ The experimenter was blind to each subject's label condition.

After ingesting the capsule, the subjects were permitted to examine the folded slip of paper. For one half of the subjects, the slip stated: "Cycloserine-mild stimulant. May cause the following reactions: increase in heart rate, increase in breathing rate, increase (slight) in body temperature." For the other half of the subjects, the slip stated: "Polymyxin-mild tranquilizer. May cause the following effects: decrease in heart rate, decrease in breathing rate, decrease (slight) in body temperature."

Following the label manipulation, the subjects were told that they would later receive either an essay written specitically for their own personality type (as indicated by the battery of personality tests which they had previously completed in class) or a control essay which had been selected at random. The subjects were informed that they would have to wait for $20 \mathrm{~min}$ for the drug to take effect and were given "the personality profile which corresponds to the essay you will read."

For one half of the subjects, the computer printout personality protile had their name at the top; for the other half of the subjects the top of the sheet read "control." In all cases, the subjects read a very general description which could conceivably be applicable to any male college student.

Following the 20 -min waiting period, the subjects were given a 4-page essay booklet to read. The booklet included a brief outline of the background of the author of the essay (fictitious) and a short. highly emotional essay which made a strong appeal for making participation in an ROTC program compulsory for all physically able male college students. This topic was chosen because it was found in the surveys administered previously in class to be highly counterattitudinal for nearly all of the subjects. For subjects in the personal condition, the essay included frequent references to the subject's own name; in the nonpersonal condition, the essay included frequent references to another person's name (always John or Tom). The essays also made reference to some of the traits described in the personality profile. The essays were individually typed for each student and contained frequent strikeovers and corrections to increase the unique, personal flavor of the essay.

After reading the essay, the subjects were given a questionnaire which included eight filler comprehension items, the dependent measure which asked the subjects to estimate the author's personal attitude on the issue of compulsory ROTC, and manipulation checks. When the subjects completed the questionnaire, they were carefully questioned for suspicions concerning the experiment and were then debriefed. 


\section{RESULTS}

\section{Checks on the Manipulations}

The subjects correctly perceived both the personalism and the label manipulations. The personalism of the communication was assessed by the following question: "How much do you feel that the essay was written personally for you?" Subjects answered on a 10-point scale, with 0 representing "not at all" and 9 "very much." The mean rating of the personal conditions was 5.07 ; in the nonpersonal conditions, the mean rating was $4.00[F(1,105)=$ 4.33, $\mathrm{p}<.05]^{5}$ Thus, subjects in the personal conditions rated the communication as being more personally written for them than subjects in the nonpersonal conditions.

The label manipulation was assessed by asking the subjects which drug they had received. All subjects were able to correctly recall the information they were given as to the nature of the drug they received.

\section{Checks for Confounding}

A second group of measures, checks for confounding (Leventhal, 1971), were also included in the dependent measures. These measures were used primarily to assess whether other critical variables such as choice were also affected by the manipulations, thus possibly accounting for any obtained differences.

The first check was to assess the subject's perception of the position taken in the essay. The subjects were asked to rate "the position taken in the essay towards compulsory ROTC" on an 81-point scale. No differences in the perceived extremity of the essay were obtained as a function of the experimental conditions (all $p>.20$ ). As intended, the subjects felt that the communication strongly supported compulsory ROTC (mean $=72.8$ ).

The second check was to assess the subject's perception of the author's choice in taking the position presented in the essay. The subjects were asked to rate "how much choice do you think the author had in taking the position presented in the essay." These ratings were made on an 81 -point scale, where 0 represented "no choice" and 80 represented "completely free choice." No differences in the perceived degree of choice of the author were obtained as a function of the experimental conditions (all $p>.20$ ). This was an interesting finding in view of Jones and Davis' (1965) suggestion that the effect of personalism may be mediated by an attribution of a high degree of choice to the actor. The mean perceived degree of choice in the high-personalism condition was 45.7 , while in the low-personalism condition, the mean was $50.0[\mathrm{~F}(1,111)<1]$. The correlation between perceived choice and perceived personalism also was not significant $(r=-.013)$. The present experiment, then, does not provide support
Table 1

Mean Attitude Attributed to the Author of the Essay

\begin{tabular}{lll} 
& \multicolumn{2}{c}{ Personalism } \\
\cline { 2 - 3 } Label & High & Low \\
\hline Tranquilizer & 66.04 & 50.60 \\
Stimulant & 50.99 & 47.96 \\
\hline
\end{tabular}

for choice as a mediator of the predicted effect of personalism.

\section{Measure of Attribution}

The measure of attribution used in the experiment was the following question: "Based on the essay and the information you have about the author, what do you think is the author's personal attitude towards making ROTC compulsory?"

Subjects answered the question on an 81-point scale, with 0 representing "extremely strongly against" and 80 "extremely strongly in favor."

The data were analyzed in a 2 by 2 ANOVA. The cell means are presented in Table 1.

The predicted effect of personalism was obtained $[\mathrm{F}(1,112)=4.59, \mathrm{p}<.05]$, with the high-personalism conditions leading to more extreme attributions than the low-personalism conditions. Also as predicted, a main effect was obtained for the label manipulation $[F(1,112)=4.21, \mathrm{p}<.05]$, with the subjects who were told that they received a tranquilizer making more extreme attributions than the subjects who were told that they had received a stimulant. Finally, the interaction of the two variables was not significant $[F(1,112)=2.08]$.

\section{DISCUSSION}

The results of the experiment support Jones and Davis' (1965) prediction that personalism increases the correspondence of an action. The manipulation of personalism was correctly perceived by the subject and it was found that, as predicted, the more personal essay led to more extreme attributions regarding the attitude of the author of the essay toward compulsory ROTC training than the less personal essay. However, Jones and Davis' suggestion that the effect of the personalism variable may be mediated by an attribution of a high degree of choice to the actor was not confirmed. The results indicate that there was no relationship between the personalism of the essay and the degree of choice which the author was perceived to have in taking the position given in the essay. This indicates that, in the present experimental situation, choice did not mediate the effect of the personalism variable.

Since choice did not mediate the personalism effect, the question arises as to how the obtained effect of personalism might be mediated. Based on the subjects' comments in the debriefing inerviews, it would seem that the personalism variable focused the 
subject's attention on the essay and its author, thus making the contents of the essay and the author's dispositions more salient. It may be that high personalism leads the subject to focus his attention on the actions of the actor, and thus he should regard these actions as important and very indicative of the underlying dispositions of the actor (Jones \& Nisbett, 1971). While this reasoning is consistent with other recent experimental evidence that attributions follow the focus of attention (Duval \& Wicklund, 1973; Storms, 1973), it remains for future research to test the proposition that the effect of personalism is mediated by shifts in the subject's focus of attention.

The second prediction was also confirmed: Subjects who were led to believe that they had received a tranquilizer made more extreme attributions regarding the attitude of the author of the essay than subjects who were led to belive that they had received a stimulant. This finding is consistent with a number of studies which have produced changes in the evaluation of emotional stimuli by leading subjects to incorrectly perceive a placebo drug as the source of their emotional arousal (Dienstbier, 1972; Nisbett \& Schachter, 1965; Ross. Rodin. \& Zimbardo. 1969; Hanson \& Blechman, Note 1). The present result also complements a previous finding by Bramel, Bell, and Margulis (1965) that subjects who received false physiological feedback indicating that they were afraid while viewing pictures of Russian leaders at tributed greater danger to Russia than subjects who nere given more neutral feedback. The present experiment together with that of Bramel et al. extends the finding of Jones and deCharms (1957) by further clarifying the nature of hedonic relevance. In both the Bramel et al. and the present experiment, interference with the subject's goal attainment was constant across conditions; only the subject's perception of his emotional response was varied. This suggests that the emotional response component is a necessary condition for obtaining effects of hedonic relevance. Whether the first component, facilitation or interference with the subject's goal attainment, is also a necessary component of what Jones and Davis have termed hedonic relevance must await future research.

\section{REFERENCE NOTE}

1. Hanson, L. R., \& Blechman, E. The labeling process during sexual intercourse. Unpublished manuscript, University of California at Los Angeles, 1970.

\section{REFERENCES}

Bramel, D., Bell, J. E., \& Margulis, S. T. Attributing danger as a means of explaining one's fear. Jourmal of Experimental Social Psychology, 1965, 1, 267-281.

DeUTSCH. M. An experimental study of the effects of cooperation and competition upon group processes. Human Relations, 1949. $2,199.232$
Dienstbier, R. A. The role of anxiety and arousal attribution in cheating. Journal of Experimental Social Psychology, 1972, 8, 168-179.

Duval, S., \& WickLUnd, R. A. Effects of objective self-awareness on the attribution of causality. Journal of Experimental Social Psychology, 19\%3, 9, 17-31.

Heider, F. Social perception and phenomenal causality. Psychological Review, 1944, 46, 358-374.

HEIDER, F. The psychology of interpersonal reiations. New York: Wiley, 1958

JoNEs, E. E. Ingratiation. New York: Appleton-Century-Crofts, 1964.

Jones, E. E., \& Davis, K. E. From acts to dispositions: The attribution process in person perception. In L. BERKowITz (Ed.), Advances in experimental social psychology (Vol. 2). New York: Academic Press, 1965.

Jones, E. E., Davis, K. E., \& Gergen, K. J. Role playing variations and their informational value for person perception. Journal of Abnormal and Social Psychology. 1961, 63, 302-310.

Jones, E. E., \& DeCharms, R. Changes in social perception as a function of the personal relevance of behavior. Sociometry, 1957 , 20, 75.85.

JoNEs, E. E., \& HARRIs, V. A. The attribution of attitudes. Journal of Experimental Social Psychology, 1967, 3, 1-24.

Jones, E. E., \& NisbetT, R. E. The actor and the observer: Divergent perceptions of the causes of behavior. Morristown, N.J: General Learning Press, 1971.

Jones, E. E., Worchel. S., Goethals, G. R., \& Grumet, J. Prior expectancy and behavioral extremity as determinants of attitude attribution. Journal of Experimental Social Psychology, 1971, 7, 59-80.

KLEINER, R. J. The effects of threat reduction on interpersonal attractiveness. Journal of Personality, 1960, 28, 145-156.

LeVenthal, H. Findings and theory in the study of fear communications. In L. BERKowITz (Ed.), Advances in experimental social psychology (Vol. 5). New York: Academic Press, 1971.

Lowe, C. A., \& Goldstein, J. W. Reciprocal liking and attributions of ability: Mediating effects of perceived intent and personal involvement. Journal of Personality and Social Psychology. 1970, 16, 291-297.

Messick, D. M., \& Reeder, G. Perceived motivation, role variations, and the attribution of personal characteristics. Journal of Experimental Social Psychology, 1972, 8, 482-491.

Mintz. P., \& Mills, J. Effects of arousal and information about its source on attitude change. Journal of Experimental Social Psychology, 1971, 7, 561-570.

NisbetT, R. E.. \& Schachter, S. Cognitive manipulation of pain. Journal of Experimental Social Psychology, 1966, 1, 227-236.

Ross. L. D.. Rodin, J., \& Zimbardo, P. G. Toward an attribu. tion therapy: The reduction of fear through cognitive-emotional misattribution. Joumal of Personality and Social Psychology. $1969.12,279-288$.

Steiner, I. D. \& Fiel. , W. L. Role assignment and interpersona intluence. Journal of Abnormal and Social Psychology, 1960. 61. $239-246$

Storms. J. D. Videotape and the attribution process: Reversing actors' and observers' points of view. Journal of Personality and Social Psychology. 1973, 27, 165-175.

Storms, M. D. \& Nisb ETt, R. E. Insomnia and the attribution process. Joumal of Personality and Social Psychology. 1970. 16, $319-328$.

\section{NOTES}

1. Correspondence is the directness of the relationship between observed action and the disposition which is offered by the observer to explain the action. According to Jones and Davis (1965, p. 224). "Correspondence increases as the judged value of the attribute departs from the judge's conception of the average person's standing on that attribute." 
2. Thirty-two subjects were eliminated from the experiment. Three subjects were eliminated because they expressed suspicion of the experimental procedures. Twenty-nine subjects were eliminated prior to assignment to experimental conditions: Twenty-two subjects had contraindicated medical histories, six subjects expressed attitudes consistent with the communication, and one subject was unable to swallow the capsule.

3. In an attempt to manipulate physiological arousal, one half of the subjects in fact received a $200-\mathrm{mg}$ dosage of caffeine, the maximum dosage considered acceptable by the university review committee whose approval was required to conduct the present research. This dosage is less than that which has normally been used to manipulate physiological arousal (e.g., $300 \mathrm{mg}$, Mintz \& Mills, 1971) and no differences were obtained in the subjects' self-reports of arousal as a function of the administration of caffeine. Consequently, the dosage used in the present experiment is interpreted as a functional placebo. The inclusion of the drug manipulation as a factor in the experiment does not change the results in any manner.

4. The results of a pilot study showed that the inclusion of the personality protile was necessary for the personalism manipulation to have impact on the subject. The use of the subject's or another name without the associated personality profile did not lead to differences between the personalism conditions on the manipulation check.

5. The error degree of freedom varies slightly between the analyses, as some subjects did not answer all of the dependent measures.

(Received for publication August 23, 1974; revision accepted November $2,1974$. 